\title{
CARBONELL, J. Pedagogias do século XXI. 3. ed. Porto Alegre: Penso, 2016. 263 p.
}

\section{Jocilene Gordiano Lima Tomaz Pereira ${ }^{1}$ Douglas Ortiz Hamermüller ${ }^{2}$}

O livro Pedagogias do Século XXI, traduzido por Juliana dos Santos Padilha e com revisão técnica de Luciana Vellinho Corso, é a mais recente obra do sociólogo, jornalista e pedagogo espanhol Jaume Carbonell. O autor, que por anos foi diretor de Cuadernos de Pedagogia, escreveu inúmeros livros sobre educação, entre os quais destacamos Pedagogias del Siglo $X X$, do qual foi um dos idealizadores e organizadores; nesse livro, foram apresentadas onze Pedagogias por meio do trabalho de onze professores que foram seus criadores ou referência para as mesmas. Essa obra anterior focava, portanto, os autores e a influência de suas ideias no pensamento sobre as práticas docentes e a constituição das escolas.

No entanto, como aponta Carbonell (2016), a histórica fronteira entre teoria e prática na área de Educação, tão amplamente discutida e analisada no campo da Pedagogia, tornou-se mais flexível. Por esse motivo, a composição organizativa, conceitual e metodológica que prospecta essa nova obra, apresenta movimentos de corporeidade de oito Pedagogias que irromperam no século XXI, revelando, na ação concreta do fazer hibridar teoria-prática, a pedagogia na contemporaneidade.

O autor, tendo por ponto de partida a questão "quais são os novos discursos e práticas pedagógicas que estão emergindo e iluminando este novo século e a partir de onde se constroem?", redireciona sua lupa analítica ao presente. Toma as pedagogias que permeiam as perspectivas educativas do século XXI a partir de um conjunto de marcas identitárias conceituais desses entrelaces e/ ou desenlaces teórico-metodológicos, onde é visível o cotejamento de singularidades e de coletividades, assim como o compartilhamento de "bases para a inovação educativa". Com esse contexto circunscreve oito Pedagogias que

DOI: $10.1590 / 0104-4060.49809$

1 Universidade Federal do Vale do São Francisco. Campus Serra da Capivara. Colegiado de Licenciatura em Ciências da Natureza. São Raimundo Nonato, Piauí, Brasil. Rua João Ferreira dos Santos, s/nº. Bairro Campestre. CEP: 64770-000.E-mail: jocilene.pereira@gmail.com

2 Universidade Federal do Paraná. Setor Litoral. Coordenação Acadêmica. Matinhos, Paraná, Brasil. Rua Jaguariaíva, nº 512. CEP: 83260-000.E-mail: douglas.ufprlitoral@gmail.com 
simultaneamente reverberaram pressupostos da contemporaneidade, constituindo os capítulos que são a espinha dorsal do livro, são elas: as pedagogias não institucionais; as pedagogias críticas; as pedagogias livres não diretivas; as pedagogias de inclusão e de cooperação; a pedagogia lenta, serena e sustentável; a pedagogia sistêmica; as pedagogias do conhecimento integrado; as pedagogias das diversas inteligências.

O autor compõe cada um dos oito capítulos seguindo a mesma estrutura, que divide em cinco seções. Inicia cada capítulo com um texto vivencial, em forma de narrativas e depoimentos; a seguir utilizando o subtítulo antecedentes e referências, apresenta os rastros históricos, memórias e ramificações genealógicas da Pedagogia em destaque; na terceira parte, que é identificada como as marcas comuns de identidade, explicita as matizes das tendências pedagógicas que dialogam ou se repelem; em seguida, são relatadas experiências educativas, apontando para as diversificadas possibilidades da vivência cotidiana; na quinta parte sugere questionamentos, conjecturas e discussões para debates futuros. Ao finalizar cada capítulo esclarece as referências consultadas e sugere leituras ${ }^{3}$ para maior aprofundamento das discussões que permeiam aquela Pedagogia.

No entanto, uma das características que torna essa obra tão densa e rica é o viés interativo com as experiências do autor, que flexibilizam a discussão das Pedagogias e permitem o trânsito entre tendências pedagógicas, escolas e projetos educativos. Por esse motivo, alguns autores podem ser abordados nas discussões acerca de mais de uma das Pedagogias discutidas ao longo do livro.

O primeiro capítulo discute as pedagogias não institucionais e a educação fora da escola. Nele há um transcurso histórico elucidado pelo autor, que perpassa o discurso de autores como Jean-Jacques Rousseau, John Dewey, Illich, Reimer, entre outros. A partir dessas bases conceituais chega à pedagogia não institucional e ao século XXI, onde as atenções às questões educacionais vão para um outro foco "cristalizando um currículo alternativo muito mais poderoso e atrativo que o do currículo escolar oficial". (CARBONELL, 2016, p. 9). Nessa tessitura, a proposta da cidade educativa ou educadora faz reverberar o Banco Comum de Conhecimento (BCC), as universidades alternativas, as cidades das crianças, os centros sociais culturais institucionais ou autogerenciados, a aprendizagem-serviço, a Wikipédia, entre outras apresentadas como experiências representativas das pedagogias não institucionais.

O segundo capítulo discute a complexa cartografia das pedagogias críticas. Entre as referências iniciais dessa pedagogia, destacam-se duas: a primeira, de Paulo Freire, que tematiza os movimentos da educação popular e libertadora e a

3 O sexto capítulo é uma exceção, pois para a Pedagogia Sistêmica não são sugeridas leituras complementares. 
pedagogia do oprimido, ambos da década de 1970, que uniam as suas lutas pelo despertar da consciência crítica, indo contra a educação bancária e incentivando a participação democrática horizontal em todos os cenários educativos, com fins de valorizar a alfabetização das pessoas adultas com ato político. A segunda referência, a Jürgen Habermas, na década seguinte, está pautada em uma de suas maiores contribuições educativas por meio da obra Teoria de la acción comunicativa. Essa premissa orientou, no campo da educação, a proposição da pesquisa crítica e da pesquisa-ação. Nutrindo-se dessas ideias de transformação educativa e social, o autor cita Henry Giroux, um dos fundadores da pedagogia crítica nos Estados Unidos, Basil Bernstein e Paul Willis, dentre outros. Entende que esse grupo encaminha a efetivação de uma pedagogia revolucionária. Narrando as experiências vivenciais dessa pedagogia, cita a educação no Movimento dos Trabalhadores Rurais Sem Terra do Brasil (MST), as Tertúlias dialógicas (Espanha) e a Universidade Transumante (Argentina).

As pedagogias livres não diretivas, enquanto alternativas para a escolarização comum, são discutidas no terceiro capítulo. Nas origens dessas pedagogias sustentam-se tentativas históricas de educar crianças fora do sistema convencional de escolarização. Essas possuem dois precursores: Jean Jacques Rousseau nas obras Emílio ou Da Educação, que propaga que educar não é mais do que deixar emergir o estado natural da criança; León Tolstoi com sua escola de Yasnaia Poliana, que abolia qualquer forma de obrigatoriedade. Ambos influenciaram a fundação da emblemática Escola e Internato Summerhill (Inglaterra), proposta por A. S. Neill em 1921, "[...] a primeira experiência sólida [...] em que se teoriza e se aplica o respeito à liberdade da criança". (CARBONELL, 2016, p. 78). As pedagogias livres se assentam em: educação em liberdade; escolha do que se quer aprender; educação multidimensional para além da razão; ambientes, materiais e possibilidades diversificados; autogoverno/constituição de uma microssociedade alternativa; o professor como facilitador; jornada de ensino flexível, sem horários e disciplinas. As três experiências dessa pedagogia que mereceram destaque nesse capítulo são: a Escola Livre Paideia (Mérida/ Extremadura); a escola psicopedagógica O Pelouro (Galícia) e o Projeto Integral León Dormindo (Equador).

A temática do quarto capítulo é ancorada nos pressupostos de uma educação inclusiva, a qual procura garantir que todas as pessoas - sem distinção de capacidades, raça ou qualquer outro traço - tenham a oportunidade de pertencer a uma aprendizagem coletiva, à vida cotidiana da escola e da comunidade. As pedagogias da inclusão e da cooperação emergem no século XXI com o grande desafio de garantir "um mundo em que todos e todas sejam socialmente iguais, humanamente diferentes e totalmente livres". (CARBONELL, 2016, p. 102). Com uma história marcada por movimentos e lutas pela supressão da 
segregação escolar e dos "guetos". (CARBONELL, 2016, p. 105) familiares e sociais de confinamentos de crianças e jovens com deficiência, essas pedagogias defendem que a inclusão é essencial para a qualidade educativa. A Declaração de Salamanca (1994) e as experiências do Programa Cooperar para Aprender/ Aprender a Cooperar (Barcelona), do Projeto INCLUD-ED (Strategies for Inclusion and Social Cohesion in Europe from Education), do Projeto Roma (Itália e Espanha) e da escola Folchi Torres são exemplificadas como iniciativas para tornar a inclusão possível.

No quinto capítulo, deparamo-nos com a seguinte questão problematizadora: "de que tempo precisa a educação que desejamos?". (CARBONELL, 2016, p. 149). As oscilantes respostas a essa questão impulsionam uma difícil articulação entre o tempo "chronos", simbolizado pelo relógio, carga horária, quantidade de dias letivos, que medem, limitam, planejam, cronometram o período de realização de qualquer atividade e o tempo "kairós", que representa o tempo da experiência "necessário para qualquer acontecimento". (CARBONELL, 2016, p. 129). Assim, a pedagogia lenta, serena e sustentável, tomada como foco de discussão, entrecruza a sua trajetória com a da construção social do tempo. Um exemplo disso é a cultura da internet, com a velocidade nas trocas de informação através das mídias sociais, da interatividade e da hibridação entre todos os meios de comunicação. Já os movimentos "Slow" sublinham a perspectiva de lentidão, a desacumulação de bens e o não acúmulo de conteúdos escolares. Essa pedagogia se mostra marcadamente influenciada por diferentes experiências pedagógicas, pautadas nas perspectivas de tempo para pensar, fazer e compartilhar, como vivenciado na Escola Fructuós Gelabert (Barcelona), de tempo dos professores, difundido pela Escola Els Alocs (Barcelona) e de alimentação saudável na escola, do Colégio Marcos del Torniello (Astúrias/Espanha).

A ressonância da educação contemporânea, que objetiva "um novo olhar para compreender o que ocorre dentro da sala de aula e com as famílias" (CARBONELL, 2016, p. 167), encontra na pedagogia sistêmica, tema do sexto capítulo, muitos dos seus conceitos nucleares, tais como: complexidade, conectividade, multidimensionalidade, contextos criativos, pertencimentos. A pedagogia sistêmica vem inspirando variadas pesquisas, grupos de estudos e diversas experiências pedagógicas, dentre elas a Rede de Pedagogia Sistêmica (composta por escolas e institutos em Barcelona), distanciando-se do pensamento lógico-linear, do dualismo entre a causa e efeito e dos estudos focados apenas em uma parte.

O enfoque do sétimo capítulo são as pedagogias do conhecimento integrado através de projetos de trabalho, em que a proposta basilar é a integração do conhecimento, alicerçada na visão transdisciplinar e na aprendizagem relacional entre conhecimento e contexto. O pressuposto de que "a informação se converte 
em conhecimento, quando estabelecem conexões, contextualiza-se, detectam-se diferenças e similitudes, organiza-se e se interpreta" (CARBONELL, 2016, p. 207), circunscreve a concepção integral da educação, a forma diferente de se pensar, de se ensinar, de se aprender e de se estar na escola assumida por essa pedagogia. Nesse cenário educativo integral fomenta-se a elaboração de projetos de trabalho constituídos na complexidade das relações e saberes que se estabelecem na sala de aula e fora dela. As experiências vivenciais perpassam todos os níveis de ensino e envolvem os mais variados temas de estudos. Dentre os projetos de trabalhos explicitados no capítulo estão os "Velázquez tem dois 'z"' (Educação Infantil) e "Como vamos ser iguais?" (Ensino Fundamental - 6 Ano - Escola Serravella, Ullastrell, Barcelona).

No último capítulo, as pedagogias das diversas inteligências evocam os estudos sobre as Inteligências Múltiplas de Howard Gardner e seus colaboradores; o conceito de Inteligência Emocional popularizado por Daniel Goleman; os pressupostos da Inteligência Funcional, da Inteligência Acadêmica ou Analítica, da Inteligência Criativa e da Inteligência Prática elaborados por Robert Sternberg. O autor explicita interconexões das diversas inteligências que se refletem no contexto escolar e transformam pensamento em ação, informações em conhecimento, habilidades e competências em inovações. Em termos práticos, esses pressupostos se concretizam nas Escolas Infantis de Reggio Emília (Itália); as inteligências múltiplas no Colégio Montserrat; as Escolas Waldorf Micael; o projeto de Filosofia para Crianças (Colégio Pau Vila de Esparraguera, Barcelona).

Retomando a frase que o autor destaca no epílogo, “[...] a memória quando se ativa, contém mais sementes de futuro do que restos do passado" (CARBONELL, 2016, p. 261), podemos dizer que a leitura dessa obra eclode seu potencial inovador no burilar de rastros históricos, entrecruzados por vínculos identitários e vivências educativas. Esse contexto composto e interessante que o autor dispõe, em cada uma das oito pedagogias discutidas, aponta para incompletudes, possibilidades futuras, enfim, para a abrangência entre teoria e prática que se fazem para além da escola.

Texto recebido em 17 de novembro de 2016. Texto aprovado em 17 de dezembro de 2016. 
